\title{
Concentrações séricas de minerais e funções hepática e renal de frangos intoxicados com aflatoxina e tratados com montmorilonita sódica
}

\author{
Carina Franciscato ${ }^{(1)}$, Sonia Terezinha dos Anjos Lopes ${ }^{(1)}$, Janio Morais Santurio(2), Patrícia Wolkmer(3), \\ Roberto Marinho Maciel(1), Maribel Trindade de Paula(1), Bruna Carolina Garmatz ${ }^{(1)}$ e Márcio Machado Costa ${ }^{(1)}$
}

(1)Universidade Federal de Santa Maria (UFSM), Centro de Ciências Rurais (CCR), Hospital Veterinário, Av. Roraima s/no, Camobi, CEP $97105-900$ Santa Maria, RS. E-mail: carinafranciscato@yahoo.com.br, sonia@smail.ufsm.br, roberto.marinho@uol.com.br, maribelvet@hotmail.com, brunagar@yahoo.com.br, marmcvet@yahoo.com.br (2)UFSM, Dep. de Microbiologia e Parasitologia, Laboratório de Pesquisas Micológicas. E-mail: santurio@ccr.ufsm.br (3)Rua Acre, no 195, apt. 301, CEP 97060-040 Santa Maria, RS. E-mail: patiwol@hotmail.com

Resumo - O objetivo deste trabalho foi avaliar as concentrações séricas de minerais e as funções hepática e renal de frangos de corte intoxicados, experimentalmente, com 3 ppm de aflatoxina, e submetidos a diferentes concentrações de montmorilonita sódica na dieta. Foram utilizados 720 frangos, machos, da linhagem Cobb, divididos em seis tratamentos: T1, dieta normal; T2, dieta com aflatoxina (3 ppm); T3, dieta com montmorilonita sódica (0,25\%); T4, dieta com aflatoxina (3 ppm) + montmorilonita sódica (0,25\%); T5, dieta com montmorilonita sódica (0,5\%); T6, dieta com aflatoxina (3 ppm) + montmorilonita sódica (0,5\%), com seis repetições por tratamento. A dieta com 3 ppm de aflatoxina (T2) resultou em uma diminuição significativa na concentração sérica de proteínas totais, albumina, globulinas e aspartato amino transferase; a concentração sérica de ácido úrico diminuiu, significativamente, na dieta com aflatoxina (3 ppm) + momtmorilonita sódica a 0,25\%; ocorreu diminuição significativa nas concentrações séricas de fósforo na dieta com aflatoxina + montmorilonita sódica a 0,5\%. A aflatoxina na concentração de 3 ppm altera a função hepática de frangos de corte; o uso da montmorilonita sódica, na concentração de $0,5 \%$, é eficaz na prevenção dos efeitos tóxicos da aflatoxina, mas diminui os níveis séricos de fósforo.

Termos para indexação: aflatoxicose, filosilicatos, proteínas, cálcio, fósforo.

\section{Seric mineral concentrations and hepatic and renal functions of chickens intoxicated by aflatoxin and treated with sodic montmorillonite}

\begin{abstract}
The objective of this work was to evaluate the seric mineral concentrations and the hepatic and renal functions of broiler chicken, experimentally intoxicated with $3 \mathrm{ppm}$ of aflatoxin, and submitted to different concentrations of sodic montmorillonite in the diet. In this study 720 Cobb’s male broiler chickens were used, which were divided in six treatments: T1, normal diet; T2, diet with aflatoxin (3 ppm); T3, diet with sodic montmorillonite $(0.25 \%)$; T4, diet with aflatoxin (3 ppm) + sodic montmorillonite $(0.25 \%)$; T5, diet with sodic montmorillonite $(0.50 \%)$; $\mathrm{T} 6$, diet with aflatoxin $(3 \mathrm{ppm})+$ sodic montmorillonite $(0.5 \%)$; with six repetitions of each treatment. The diet with 3 ppm of aflatoxin resulted in a significant decrease in serum concentrations of total protein, albumin, globulins and aspartate aminotransferase; there was significant decrease of seric concentration of uric acid in the diet with aflatoxin $(3 \mathrm{ppm})+0.25 \%$ sodic montmorillonite; in the diet with aflatoxin $+0.5 \%$ sodic montmorillonite there was significant decrease in seric concentrations of phosphorus. Aflatoxin in the diet (3 ppm) causes change in the hepatic function of broiler chickens. The use of $0.5 \%$ sodic montmorillonite is effective in preventing the toxic effects of aflatoxins, but causes decrease in phosphorus seric levels.
\end{abstract}

Index terms: aflatoxicosis, phyllosilicates, proteins, calcium, phosphorus.

\section{Introdução}

As aflatoxinas são contaminantes naturais de alimentos (Kurtzman et al., 1987) e estão entre as mais importantes micotoxinas (Osweiler, 1990); a maioria das micotoxicoses são causadas por produtos agrícolas contaminados, tais como: trigo, milho, arroz, sorgo e aveia (Kedera et al., 1999). Danos mecânicos nos grãos ocorrem no transporte, na limpeza, na secagem e na colheita, dando origem a grãos quebrados e trincados, o que aumenta o teor de umidade destes e favorece o desenvolvimento de fungos. Portanto, o grão de milho, 
que representa importante papel na avicultura, em condições inadequadas de armazenamento, pode sofrer perdas no valor quantitativo e qualitativo, em razão do ataque de pragas e fungos, desde o campo até a época de consumo (Stringhini et al., 2000). Um quarto dos grãos produzidos no mundo está contaminado por micotoxinas (Santurio, 2000); por isso, o uso de produtos contaminados pela aflatoxina, para fabricação de rações, tem sido um grande problema para a indústria avícola, e vem causando sérias implicações econômicas (Ledoux et al., 1998).

Quanto à composição química, as aflatoxinas são metabólitos produzidos pelos fungos Aspergillus flavus, A. parasiticus, e possuem efeitos tóxicos agudos, mutagênicos, carcinogênicos e teratogênicos nos seres humanos e em várias espécies domésticas (Wyatt, 1991), pois essas toxinas exercem antagonismo ao metabolismo das vitaminas, proteínas e aminoácidos, lipídios e carboidratos e agem sobre coenzimas ou complexos enzimáticos, principalmente no fígado, além de afetar a estrutura química do DNA (Kiessling, 1986).

A extrema toxicidade das aflatoxinas para as aves pode ser explicada pela sua rápida absorção no trato gastrintestinal, sendo o fígado o órgão-alvo da aflatoxicose nessa espécie. Vários efeitos tóxicos podem ser causados por esta micotoxina nas aves, que incluem diminuição da performance, patologias hepáticas, imunossupressão e mudanças no peso relativo dos órgãos (Wyatt, 1991). O fígado, caracteristicamente, fica pálido e aumentado de volume como resultado de aflatoxicoses, com alterações microscópicas como degeneração gordurosa, necrose hepática e hiperplasia biliar (Ledoux, 1998).

A determinação dos efeitos bioquímicos tóxicos da aflatoxina é importante para o diagnóstico de aflatoxicose em frangos de corte (Rosa et al., 2001). A sua toxicidade, nestes animais, é caracterizada pela diminuição das concentrações de proteína total, albumina, colesterol, glicose, ácido úrico, P inorgânico e Ca, e pelo aumento da atividade enzimática da aspartato aminotransferase (AST) e da alanina aminotransferase (ALT), indicativos de lesões hepáticas (Santurio et al., 1999).

Entre os métodos existentes para minimizar os efeitos tóxicos da aflatoxicose nas aves, o mais freqüentemente utilizado é a ligação irreversível da aflatoxina a um adsorvente (Diaz et al., 2002). Segundo Olver (1997), os adsorventes possuem a habilidade de se aderir fisicamente à aflatoxina e impedir sua absorção pelo trato gastrintestinal. A montmorilonita sódica (bentonita sódica) está no grupo dos filosilicatos e é uma substância naturalmente abundante, que apresenta área de superfície de $800 \mathrm{~m}^{2} \mathrm{~g}^{-1}$, o que a torna um material adsorvente ideal (Phillips et al., 2002). Na composição dessa argila estão presentes elementos como $\mathrm{Al}, \mathrm{Fe}, \mathrm{Na}$ e Mg; além disso, as argilas podem interagir com nutrientes, minerais e outros componentes químicos da dieta (Wiles et al., 2004).

O objetivo do trabalho foi avaliar os impactos da aflatoxina, na concentração de 3 ppm, e da montmorilonita sódica sobre o metabolismo do $\mathrm{Ca}, \mathrm{P}$ e $\mathrm{Mg}$, e sobre as funções hepática e renal de frangos de corte, bem como avaliar a eficácia de proteção do referido adsorvente contra os efeitos tóxicos da aflatoxina.

\section{Material e Métodos}

Foram utilizadas 720 aves de linhagem Cobb, machos, provenientes do incubatório do Setor de Avicultura, do Dep. de Zootecnia, da UFSM. As aves foram mantidas do 1 o ao $42 \underline{0}$ dia de vida, neste mesmo setor, separadas em 36 lotes, com 20 aves por box, divididas em seis tratamentos, com seis repetições por tratamento. O programa de iluminação utilizado foi constante, com 24 horas de luminosidade, nos primeiros 21 dias de idade, e depois apenas com iluminação natural, para reduzir o estresse das aves. A água foi fornecida ad libitum durante todo o experimento. A ração foi formulada de acordo com a fase de desenvolvimento das aves (Tabela 1).

O experimento foi constituído de seis tratamentos: T1 (controle), dieta normal; T2, dieta com 3 ppm de aflatoxina; T3, dieta com $0,25 \%$ de montmorilonita sódica; T4, dieta com 3 ppm de aflatoxina $+0,25 \%$ de montmorilonita sódica; $\mathrm{T} 5$, dieta com $0,5 \%$ montmorilonita sódica; e T6, dieta com 3 ppm de aflatoxina $+0,5 \%$ montmorilonita sódica.

Tabela 1. Composição química estimada das dietas basais, para frangos de corte, nas fases inicial, de crescimento e final.

\begin{tabular}{lccc}
\hline Composição química & \multicolumn{3}{c}{ Fases } \\
\cline { 2 - 4 } & $\begin{array}{c}\text { Inicial } \\
(1-21 \text { dias })\end{array}$ & $\begin{array}{c}\text { Crescimento } \\
(22-36 \text { dias })\end{array}$ & $\begin{array}{c}\text { Final } \\
(36-42 \text { dias })\end{array}$ \\
\hline Proteína bruta (\%) & 22,00 & 20,00 & 20,00 \\
Energia metabolizável $\left(\mathrm{kcal} \mathrm{kg}^{-1}\right)$ & 3.050 & 3.100 & 3.200 \\
Cálcio (\%) & 1,00 & 0,96 & 0,90 \\
Fósforo útil (\%) & 0,45 & 0,45 & 0,40 \\
Lisina (\%) & 1,30 & 1,17 & 1,10 \\
Metionina (\%) & 0,56 & 0,54 & 0,52 \\
Metionina + cistina (\%) & 0,92 & 0,89 & 0,88 \\
Treonina (\%) & 0,80 & 0,71 & 0,71 \\
Triptofano (\%) & 0,20 & 0,22 & 0,22 \\
\hline
\end{tabular}


A aflatoxina foi produzida pelo Laboratório de Pesquisas Micológicas (Lapemi), da UFSM, conforme metodologia de Shotwell et al. (1966), a partir da fermentação controlada do fungo Aspergillus parasiticus, cepa NRRL 2999, em arroz parboilizado. A aflatoxina e a montmorilonita sódica foram adicionadas à ração durante a formulação desta.

Quando os frangos atingiram 42 dias de idade, foram selecionadas, aleatoriamente, 12 aves de cada tratamento, num total de 72 aves. De cada ave, foram coletados $10 \mathrm{~mL}$ de sangue, por punção cardíaca, depois da dessensibilização por corrente elétrica. O soro foi separado por centrifugação e estocado a $-20^{\circ} \mathrm{C}$ para posterior análise das concentrações séricas de $\mathrm{Ca}, \mathrm{P}$, Mg, proteínas totais, albumina, AST, ácido úrico e uréia. As provas bioquímicas foram efetuadas por meio de processo cinético, em analisador semi-automático. As globulinas foram determinadas pela diferença entre proteínas e albumina.

A análise estatística dos dados obtidos incluiu análise de variância, teste $\mathrm{F}$ e teste de Tukey a $5 \%$ de probabilidade, usando o SAS (SAS Institute, 2000).

\section{Resultados e Discussão}

Não houve diminuição nas concentrações de Ca sérico (Tabela 2), o que difere dos relatos de Eraslan et al. (2005), que descrevem diminuição na concentração sérica deste mineral, na toxicose causada por aflatoxinas em aves. Porém, estes resultados estão de acordo com Desheng et al. (2005), que não observaram diferenças nas concentrações sangüíneas de $\mathrm{Ca}$, em aves afetadas por aflatoxicose. Também, não se observou variação do mineral, nos níveis sangüíneos das aves que receberam montmorilonita sódica na dieta, à semelhança de Desheng

Tabela 2. Concentrações séricas de cálcio, fósforo e magnésio, em frangos de corte intoxicados, experimentalmente, com aflatoxina e submetidos a diferentes concentrações de montmorilonita sódica (MMS) ${ }^{(1)}$.

\begin{tabular}{ccccccc}
\hline Tratamento & \multicolumn{2}{c}{ Composição } & & \multicolumn{3}{c}{ Minerais séricos } \\
\cline { 2 - 3 } \cline { 6 - 7 } & $\begin{array}{c}\text { Aflatoxina } \\
(\mathrm{ppm})\end{array}$ & $\begin{array}{c}\text { MMS } \\
(\%)\end{array}$ & & $\begin{array}{c}\text { Cálcio } \\
\left(\mathrm{mg} \mathrm{dL}^{-1}\right)\end{array}$ & $\begin{array}{c}\text { Fósforo } \\
\left(\mathrm{mg} \mathrm{dL}^{-1}\right)\end{array}$ & $\begin{array}{c}\text { Magnésio } \\
\left(\mathrm{mg} \mathrm{dL}^{-1}\right)\end{array}$ \\
\hline T1 & 0 & 0,00 & & $10,63 \mathrm{a}$ & $8,10 \mathrm{a}$ & $2,64 \mathrm{a}$ \\
T2 & 3 & 0,00 & & $9,10 \mathrm{a}$ & $7,71 \mathrm{ab}$ & $2,50 \mathrm{a}$ \\
T3 & 0 & 0,25 & & $9,28 \mathrm{a}$ & $7,10 \mathrm{ab}$ & $2,82 \mathrm{a}$ \\
T4 & 3 & 0,25 & & $9,83 \mathrm{a}$ & $6,65 \mathrm{ab}$ & $2,69 \mathrm{a}$ \\
T5 & 0 & 0,50 & & $9,10 \mathrm{a}$ & $7,37 \mathrm{ab}$ & $2,58 \mathrm{a}$ \\
T6 & 3 & 0,50 & & $9,79 \mathrm{a}$ & $6,54 \mathrm{~b}$ & $2,62 \mathrm{a}$ \\
\hline
\end{tabular}

${ }^{(1)}$ Médias seguidas de letras distintas, nas colunas, diferem entre si a 5\% de probabilidade. et al. (2005), que embora tenham utilizado montmorilonita de cálcio, relataram que o adsorvente não afetou a concentração sérica de Ca.

Ocorreu diminuição significativa, nas concentrações séricas de $\mathrm{P}$ dos animais tratados com aflatoxina e 0,5\% de montmorilonita sódica (Tabela 2), o que concorda com Santurio et al. (1999), que observaram redução de $30 \%$ das concentrações séricas de $\mathrm{P}$, em razão da inclusão do adsorvente. Eraslan et al. (2005) consideram que esta diminuição resulta da alta capacidade adsorvente da bentonita sódica (montmorilonita sódica), que pode adsorver também Ca e P, não só a aflatoxina, no trato gastrintestinal. Porém, neste trabalho, não ocorreu a adsorção do Ca, somente do P.

Não houve alterações nas concentrações séricas de Mg (Tabela 2), o que indica que a aflatoxina não afeta o metabolismo deste mineral. Chestnut et al. (1992) relataram que o uso do adsorvente aluminosilicato sódiocálcio hidratado (HSCAS) em ovelhas prejudicou a absorção de Mg. Neste trabalho, o uso de montmorilonita sódica, na formulação da ração para as aves, não alterou as concentrações séricas desse mineral, portanto, esse adsorvente, nas concentrações de 0,25 e 0,5\%, não afeta a absorção intestinal de Mg. Apesar de esta argila possuir Mg, em sua composição (Wiles et al., 2004), não foi observado aumento nas concentrações séricas desse elemento.

Conforme Keçeci et al. (1998), a diminuição das concentrações séricas de proteína e albumina são indicadores confiáveis de hepatotoxicidade em frangos e perus, em conseqüência da aflatoxicose. Neste trabalho, observou-se diminuição da proteína total, albumina e globulinas, nas aves que receberam somente aflatoxina (Tabela 3), o que concorda com os resultados obtidos por Harvey et al. (1988), Batina et al. (2005) e Celik et al. (2005), que também obtiveram diminuição de proteínas totais e albumina, em intoxicações experimentais por aflatoxina, portanto, infere-se que as aves apresentaram comprometimento de suas funções hepáticas.

Houve diminuição significativa nos níveis de AST, nas aves tratadas somente com aflatoxina (T2), quando comparadas com as de outros tratamentos (Tabela 3), o que difere de Batina et al. (2005) que, mesmo com utilização de uma concentração de 5 ppm de aflatoxina, não encontraram alterações nos níveis séricos desta enzima em seu trabalho. Como as aves do tratamento 2 apresentaram diminuição da função hepática, caracterizada por diminuição da proteína total, albumina e globulinas, a diminuição dos níveis séricos de AST 
Tabela 3. Concentrações séricas de proteínas totais, albumina, aspartato aminotransferase (AST), ácido úrico e uréia, em frangos de corte intoxicados, experimentalmente, com aflatoxina e submetidos a diferentes concentrações de montmorilonita sódica $(\mathrm{MMS})^{(1)}$.

\begin{tabular}{|c|c|c|c|c|c|c|c|c|}
\hline \multirow[t]{2}{*}{ Tratamento } & \multicolumn{2}{|c|}{ Composição } & \multicolumn{6}{|c|}{ Parâmetros séricos } \\
\hline & $\begin{array}{l}\text { Aflatoxina } \\
\text { (ppm) }\end{array}$ & $\begin{array}{c}\text { MMS } \\
(\%)\end{array}$ & $\begin{array}{c}\text { Proteína } \\
\left(\mathrm{g} \mathrm{dL}^{-1}\right)\end{array}$ & $\begin{array}{l}\text { Albumina } \\
\left(\mathrm{g} \mathrm{dL}^{-1}\right)\end{array}$ & $\begin{array}{c}\text { Globulina } \\
\left(\mathrm{g} \mathrm{dL}^{-1}\right)\end{array}$ & $\begin{array}{c}\text { AST } \\
\left(\mathrm{U} \mathrm{L}^{-1}\right)\end{array}$ & $\begin{array}{l}\text { Ácido úrico } \\
\left(\mathrm{mg} \mathrm{dL}^{-1}\right)\end{array}$ & $\begin{array}{c}\text { Uréia } \\
\left(\mathrm{mg} \mathrm{dL}^{-1}\right)\end{array}$ \\
\hline $\mathrm{T} 1$ & 0 & 0,00 & $3,17 \mathrm{a}$ & $1,16 \mathrm{a}$ & $2,01 \mathrm{a}$ & $307,08 \mathrm{ab}$ & $5,80 \mathrm{ab}$ & $3,33 a$ \\
\hline $\mathrm{T} 2$ & 3 & 0,00 & $1,75 b$ & $0,79 b$ & $0,96 \mathrm{~b}$ & $255,25 b$ & $5,00 \mathrm{ab}$ & $4,16 a$ \\
\hline T3 & 0 & 0,25 & $2,99 a$ & $1,24 \mathrm{a}$ & $1,75 \mathrm{a}$ & $342,33 a$ & $6,07 \mathrm{ab}$ & $2,75 \mathrm{a}$ \\
\hline $\mathrm{T} 4$ & 3 & 0,25 & $2,66 \mathrm{a}$ & $0,98 \mathrm{ab}$ & $1,68 \mathrm{a}$ & $262,08 \mathrm{ab}$ & $4,55 b$ & $3,58 \mathrm{a}$ \\
\hline T5 & 0 & 0,50 & $2,94 a$ & $1,22 \mathrm{a}$ & $1,72 \mathrm{a}$ & $323,25 \mathrm{ab}$ & $6,65 a$ & $2,75 a$ \\
\hline T6 & 3 & 0,50 & $3,02 \mathrm{a}$ & $1,23 \mathrm{a}$ & $1,79 \mathrm{a}$ & $277,58 \mathrm{ab}$ & $5,47 \mathrm{ab}$ & $3,66 \mathrm{a}$ \\
\hline
\end{tabular}

(1)Médias seguidas de letras distintas, nas colunas, diferem entre si a 5\% de probabilidade.

implica que essas aves estavam desenvolvendo um comprometimento hepático, pois Harvey et al. (1988) e Miazzo et al. (2005) relataram, respectivamente, alterações histológicas, como fibrose interlobular e vacuolização citoplasmática peritubular, no fígado de aves com aflatoxicose e, conforme explica Fudge (2000), um fígado em estágio final, como na severa fibrose ou lipidose, pode produzir pouco extravasamento hepatocelular, o que resulta em níveis normais ou diminuídos de AST.

No soro das aves alimentadas com 3 ppm de aflatoxina, observou-se diminuição numérica na concentração de ácido úrico (Tabela 3); embora não significativa, essa alteração pode ser uma das conseqüências da aflatoxina sobre a função hepática, pois este metabólito é sintetizado no fígado (Lumeij, 1997). Com a adição de montmorilonita sódica na dieta das aves, as concentrações séricas de ácido úrico diminuíram significativamente, o que mostra que a montmorilonita, na concentração de $0,25 \%$, não foi capaz de prevenir os efeitos tóxicos da aflatoxina sobre o metabolismo do ácido úrico. A diminuição sérica de ácido úrico está de acordo com Batina et al. (2005), que observaram resultados semelhantes em frangos com aflatoxicose experimentalmente induzida. Essa menor concentração de ácido úrico em tratamentos com aflatoxina pode ser um reflexo da diminuição das proteínas, pois segundo Lumeij (1997), o ácido úrico é o produto final do metabolismo protéico nas aves.

As aves dos T4 e T6, que receberam 3 ppm de aflatoxina em dietas adicionadas de $0,25 \%$ e $0,5 \%$ de montmorilonita sódica, respectivamente, não apresentaram diminuição nas concentrações séricas de proteína total, albumina e globulinas (Tabela 3); isto mostra que $0,25 \%$ do adsorvente foi capaz de prevenir os efeitos tóxicos de $3 \mathrm{ppm}$ de aflatoxina sobre esses parâmetros, o que não acontece quando a concentração de aflatoxina é de 5 ppm, conforme descrito por Batina et al. (2005). Nesses mesmos tratamentos, também não houve a diminuição da AST, o que comprova o efeito protetor desse adsorvente sobre as alterações no tecido hepático, produzidas pela aflatoxina, resultado que concorda com Miazzo et al. (2005), que observaram redução da incidência e da severidade das alterações histopatlógicas, em aves que receberam aflatoxina e montmorilonita sódica associadas.

Esse adsorvente só evitou a diminuição sérica de ácido úrico, quando foi administrado na concentração de $0,5 \%$, o que está de acordo com Santurio et al. (1999) e Batina et al. (2005), que utilizaram o mesmo adsorvente, em frangos de corte intoxicados por aflatoxina na dieta, e concluíram que a adição de montmorilonita sódica, nesta concentração, é capaz de prevenir os efeitos da aflatoxicose.

\section{Conclusão}

1. A aflatoxina na concentração de 3 ppm diminui a função hepática, evidenciada pela diminuição das concentrações séricas de proteína total, albumina, globulinas e aspartato aminotransferase.

2. O uso da montmorilonita sódica, na concentração de $0,5 \%$, é eficaz na prevenção dos efeitos tóxicos da aflatoxina sobre a função hepática.

\section{Agradecimentos}

Ao Prof. José Henrique Souza da Silva, pela orientação nas análises estatísticas. 


\section{Referências}

BATINA, P.N.; LOPES, S.T.A.; SANTURIO, J.M.; SOUZA, C.; MARTINS, D.B. Efeitos da adição de montmorilonita sódica na dieta sobre o perfil bioquímico de frangos de corte intoxicados com aflatoxina. Ciência Rural, v.35, p.826-831, 2005.

ÇELIK, S.; ERDOAN, Z.; ERDOAN, S.; BAL, R. Efficacy of tribasic copper chloride (TBCC) to reduce the harmful effects of aflatoxin in broilers. Turkish Journal of Veterinary and Animal Science, v.29, p.909-916, 2005.

CHESTNUT, A.B.; ANDERSON, P.D.; COCHRAN, M.A.; FRIBOURG, H.A.; GWINM, K.D. Effects of hidrated sodium calcium aluminosilicate on fescue toxicosis and mineral absorption. Journal of Animal Science, v.70, p.2838-2846, 1992.

DESHENG, Q.; FAN, L.; YNHU, Y.; NIYA, Z. Adsorption of aflatoxin $\mathrm{B}_{1}$ on montmorillonite. Poultry Science, v.84, p.959-961, 2005.

DIAZ, D.E.; HAGLER JUNIOR, W.M.; HOPKINS, B.A.; WHITLOW, L.W. Aflatoxin binders I: in vitro binding assay for aflatoxin $B_{1}$ by several potential sequestering agents. Mycopathologia, v.156, p.223-226, 2002.

ERASLAN, G.; ESSIZ, D.; AKDOGAN, M.; SAHINDOKUYUCU, F.; ALTINTAS, L. The effects of aflatoxin and sodium bentonite combined and alone on some blood electrolyte levels in broiler chickens. Turkish Journal of Veterinary and Animal Science, v.29, p.601-605, 2005.

FUDGE, A.M. Avian liver and gastrointestinal testing. In: FUDGE, A.M. Laboratory Medicine: avian and exotic pets. Philadelphia: W.B. Saunders Company, 2000. p.35-55.

HARVEY, R.B.; HUFF, W.E.; KUBENA, L.F.; CORRIER, D.E.; PHILLIPS, T.S. Progression of aflatoxicosis in growing barrows. American Journal of Veterinary Research, v.49, p.482-487, 1988.

KEÇECI, T.; OGUZ, H.; KURTOGLU, V.; DEMET, O. Effects of polyvinylpolyrrolidone, synthetic zeolite and bentonite on serum biochemical and haematological characters of broiler chickens during aflatoxicosis. British Poultry Science, v.39, p.452-458, 1998.

KEDERA, C.J.; PLATTNER, R.D.; DESJARDINS, A.E. Incidence of Fusarium spp. and levels of fumonisin B1 in maize in Western Kenya. Applied and Environmental Microbiology, v.65, p.41-45, 1999.

KIESSLING, K. Biochemical mechanism of action of mycotoxins. Pure and Applied Chemistry, v.58, p.327-328, 1986.

KURTZMAN, C.P.; HORN, B.W.; HESSELTINE, C.W. Aspergillus nomius, a new aflatoxin-producing species related to Aspergillus flavus and Aspergillus tamarii. Antonie van Leeuwenhoek, v.53, p.147-158, 1987.

LEDOUX, D.R.; ROTTINGHAUS, G.E.; BERMUDEZ, A.J.; ALONSO-DEBOLT, M. Efficacy of hydrated sodium calcium aluminosilicate to ameliorate the toxic effects of aflatoxin in broiler chickens. Poultry Science, v.77, p.204-210, 1998.
LUMEIJ, J.T. Avian clinical biochemistry. In: KANEKO, J.J.; HARVEY, J.W.; BRUSS, M.L. Clinical biochemistry of domestic animals. $5^{\text {th }}$ ed. London: Academic Press, 1997. p.857-883.

MIAZZO, R.; PERALTA, M.F.; MAGNOLI, C.; SALVANO, M.; FERRERO, S.; CHIACCHIERA, S.M.; CARVALHO, E.C.Q.; ROSA, C.A.R.; DALCERO, A. Efficacy of sodium bentonite as a detoxifier of broiler feed contaminated with aflatoxin and fumonisin. Poultry Science, v.84, p.1-8, 2005.

OLVER, M.D. Effects of feeding clinoptilolite (zeolite) on the performance of three strains of laying hens. Poultry Science, v.38, p.220-222, 1997.

OSWEILER, G.D. Mycotoxins and livestock: what role do fungal toxins play in illness and production losses? Veterinary Medicine, v.85, p.89-94, 1990.

PHILLIPS, T.D.; LEMKE, S.L.; GRANT, P.G. Characterization of clay-based enterosorbents for the prevention of aflatoxins. In: DEVRIES, J.W.; TRUCKSESS, M.W.; JACKSON, L.S. Mycotoxins and food safety. New York: Kluwer Academic/Plenum Publishers, 2002. p.157-171.

ROSA, C.A.R.; MIAZZO, R.; MAGNOLI, C.; SALVANO, M.; CHIACCHIERA, S.M.; FERRERO, S.; SALUZ, M.; CARVALHO, E.C.Q.; DALCERO, A. Evaluation of the efficacy of bentonite from the South of Argentina to ameliorate the toxic effects of aflatoxin in broilers. Poultry Science, v.80, p.139144, 2001.

SANTURIO, J.M. Micotoxinas e micotoxicoses na avicultura. Revista Brasileira de Ciência Avícola, v.2, p.1-12, 2000.

SANTURIO, J.M.; MALLMANN, C.A.; ROSA, A.P.; APPEL, G.; HEER, A.; DAGEFORDE, S.; BOTTCHER, M. Effect of sodium bentonite on performance and blood variables of broiler chickens intoxicated with aflatoxins. British Poultry Science, v.40, p.115119, 1999.

SAS INSTITUTE (Cary, Estados Unidos). SAS user's guide: statistics version 8.02 for Windows. Cary, 2000. Não paginado.

SHOTWELL, O.L.; HESSELTINE, C.W.; STUBBLEFIELD, R.D.; SORENSON, W.G. Production of aflatoxin on rice. Applied Microbiology, v.14, p.425-428, 1966.

STRINGHINI, J.H.; MOGYCA, N.S.; ANDRADE, M.A.; ORSINE, G.F.; CAFÉ, M.B.; BORGES, S.A. Efeito da qualidade do milho no desempenho de frangos de corte. Revista Brasileira de Zootecnia, v.29, p.191-198, 2000.

WILES, M.C.; HUEBNER, H.J.; AFRIYIE-GYAWU, E.; TAYLOR, R.J.; BRATTON, G.R.; PHILLIPS, T.D. Toxicological evaluation and metal bioavailability in pregnant rats following exposure to clay minerals in the diet. Journal of Toxicology and Environmental Health, v.67, p.863-874, 2004.

WYATT, R.D. Poultry. In: SMITH, J.E.; HENDENSON, R.S. Mycotoxins and animal foods. Boca Raton: CRC Press, 1991. p.553-605. 